\title{
A IMPORTÂNCIA DA FILOSOFIA NA DOCÊNCIA DO ENSINO SUPERIOR NOS CURSOS DE LICENCIATURA
}

\author{
THE IMPORTANCE OF PHILOSOPHY IN THE TEACHING OF HIGHER EDUCATION \\ IN THE LICENSEE COURSES
}

Janio Robson Rocha Lima ${ }^{1}$

\begin{abstract}
RESUMO: A filosofia como uma maneira de alcançar as conexões estabelecidas no mundo, favorece uma reflexão profunda dos problemas existentes no contexto econômico, cultural, social, político e educacional. Ponderando que a educação está enveredada por ideias, valores e finalidades, portanto cabe a nós refletirmos sobre o verdadeiro sentido e valor que ela possui na e para a sociedade. Com efeito, esse estudo versa sobre a cadeia do pensamento, e da reflexão filosófica na perspectiva educacional, tendo em vista o valor desse campo para a formação dos acadêmicos, tendo como objetivo principal, examinar acerca da relevância da Filosofia para os docentes em processo de formação, além de fundamentar esse processo a partir de estudos bibliográficos, nas perspectivas do pensamento de Freire, Luckesi e Saviani. Evidenciado assim a real importância da Filosofia para a conjectura educacional, e, sobretudo na vida e no processo de ensino do educador. Uma vez que a partir dessa abordagem possamos refletir melhor sobre o real valor da filosofia e da reflexão filosófica na formação e desenvolvimento do educador, de maneira a nortear uma prática educativa que seja transformadora do contexto educacional do educador.
\end{abstract}

Palavras-Chave: Filosofia. Educação. Formação nível superior.

ABSTRACT: Philosophy to reach established connections in the world, favors a deep reflection of the problems existing in the economic, cultural, social, political and educational context. Pondering that education is driven by ideas, values and purposes, so it is up to us to reflect on the true meaning and value it has in and for society. In fact, this study deals with the chain of thought and of philosophical reflection within the educational perspective, considering the value of this field for the formation of academics, with the main objective of examining the relevance of Philosophy for in-process teachers and to base this process from bibliographical studies on the perspectives of Freire, Luckesi and Saviani. Thus, the real importance of Philosophy for the educational conjecture, and above all in the educator's life and teaching process. Once this approach can better reflect on the real value of philosophy and philosophical reflection in the formation and development of the educator, in order to guide an educational practice that is transforming the educational context of the educator.

Keywords: Philosophy. Education. Higher education.

\footnotetext{
${ }^{1}$ Professor licenciado em Filosofia da Universidade Estadual Vale do Acaraú- UVA, graduado em Pedagogia pela Faculdade da Lapa- FAEL, acadêmico de Ciências Biológicas do Instituto Federal de Ciências do CearaIFCE, acadêmico de Ciências Contábeis - Anhanguera e especialista em Docência do Ensino Superior pela Intervalen e professor de Filosofia na EEEP.Júlio França. E-mail: Janyo_lima@hotmail.com.
} 


\section{INTRODUÇÃO}

A prática de filosofar, bem como o ensino de filosofia, não se limita a simples maneira de falar em um campo de especulação ou de repasse de conceitos. Sendo assim, podemos entender que estudar filosofia no ensino superior está bem além do contexto superficial a qual ela se mantém nos dias de hoje, ou seja, a mesma só deve interessar aos estudantes de filosofia, o que não é bem uma verdade.

Educar na contemporaneidade é uma tarefa muito difícil, tanto é que enquanto educadores não podemos ditar somente regras, pois no geral somos tidos como os senhores da verdade e do agir, além de que nesse mesmo universo nos deparamos constantemente com realidades sociais diferentes, e que elas não estejam tão distantes de uma visão que seja excludente dos mecanismos educacionais vigentes.

A docência requer uma abordagem muito peculiar, isto por se tratar de um aspecto fundamental na vida de um indivíduo, que vai além de entender um rol de conteúdos o aluno enquanto ser que aprende, está inserido na sociedade como participante atuante dos padrões elitistas. Sendo assim, muito se dialoga atualmente sobre um ensino mais voltado para a conviç̧ão do ser como protagonista das suas próprias histórias, entretanto nada é efetivamente desenvolvido.

Diante disso, esse estudo tem por objetivo esclarecer sobre a importância que a reflexão filosófica tem na formação do docente no ensino superior nos cursos de licenciatura do ensino superior, melhorando assim sua maneira crítica e reflexiva de pensar. Contudo sabemos que as didáticas as quais estamos acostumados não surtem mais efeitos, pois os tempos mudam e a maneira de raciocinar também, desse modo vivemos em uma constante mudança, seja de nossa prática, ou mesmo muitas outras que são relativamente significativas em nossas vidas. O contexto social ao qual se eleva à nossa maneira de pensar, ou de expor argumentos, prediz um estado de muito julgo, mesmo sendo essa a realidade do meio em que o indivíduo está situado.

Não podemos sobre hipótese alguma desacatar os métodos costumeiros de ensino de filosofia dos dias atuais, ou seja, apenas o uso de livros didáticos e de textos. Mas devemos sim, atrelar esse conhecimento a um marco histórico, ou seja, trazer os debates e demais especificações dos primórdios da filosofia para nossa época, sem desprezar qualquer fundamento que possa ser importante para uma melhor compressão dos aspectos filosóficos atualmente, e nesse contexto incutirem a importância da consciência e visão filosófica para os estudantes dos cursos de licenciatura do nível superior.

Nos últimos tempos alguns estudiosos e filósofos como Cipriano Luckesi, Demerval Saviani, Paulo Freire e Silvio Gallo, estudiosos esses que fazem parte do referencial desse trabalho e 
que também se dedicaram a compreender a importância da filosofia para a formação dos educadores e de modo singular o uso da disciplinas no nível superior, partindo assim do princípio norteador, para que este venha a assegurar o docente a interagir consigo mesmo, ao passo de poder se questionar quanto ao seu papel como agente transformador, pois não se deve agarrar-se a um modelo de ensino engessado onde o aprendiz não possa expor seus argumentos diante da realidade a qual está vivenciando. Deve sim, existir um intermédio que realce essa qualidade para que ele possa através do principio da finalidade conseguir situar-se como tal, dentro da condição que lhe for imposta. Pois é a partir desse prospecto que ele poderá atingir seus potenciais.

Enfim, o objetivo desse estudo consiste em melhorar a formação do docente no ensino superior, a partir de uma reflexão filosófica, onde o fulcro principal está na forma como ele utiliza o conhecimento filosófico, para assim construir seu raciocínio e sua formação reflexiva, aumentando consideravelmente seu conhecimento, e fornecendo assim um maior apoio pedagógico, que intrinsecamente é fundamental para bom êxito e desenvoltura do processo de ensino no ambiente educacional, e, por conseguinte a isso melhorar as condições essenciais do método de ensino filosófico. Fazendo isso a partir dos conceitos de reflexão e de criticidade permitindo assim que o ensino e a formação dentro do campo da filosofia possam melhorar significativamente os pilares da educação filosófica, não somente para nossos educadores mais também para o próprio sistema educacional.

\section{FILOSOFIA E A PRÁTICA DE FILOSOFAR}

À Filosofia surgira no final do século VII e início do VI A.C. na Antiga Grécia. Resultado de um processo lento e gradativo, para que assim pudesse contribuir para vários fatores que ainda hoje repercutem em nosso meio, como as viagens marítimas, a invenção da escrita, a invenção da moeda, o nascimento da pólis ou cidade estado. (FERNANDES, 2006),

Com efeito, os primeiros filósofos tinham uma preocupação cosmológica e foram posteriormente denominados pré-socráticos. E é nesse cenário que a Filosofia surge em um mundo povoado por concepções míticas e em oposição a elas. O mito é considerado a forma mais primitiva de compreensão da realidade. Tratando-se, pois de um tipo de saber que é coletivo afetivo e dogmático. Todavia os mitos são mantidos vivos pela tradição e cumprem uma importante função de atribuir sentido ao mundo, de explicar a realidade, de ordenar o caos. Uma vez que esses primeiros filósofos desconfiavam das explicações míticas, pois elas não ofereciam uma sistemática que fosse capaz de explicar formalmente as coisas ou questionamentos e passaram assim a buscar uma explicação racional para o existente. Dessa forma, a Filosofia surge se opondo a uma visão mítica e 
predominante na época e vai configurando-se posteriormente como uma reflexão racional para tentar a explicação do existente. (CHAUI, 2010. pg.28)

De acordo com Bezerra (2015), sabemos que a prática do filosofar está cada vez mais presente dentro das perspectivas educacionais, pois sabemos que é através da reflexão e do questionamento que conseguimos extrair conhecimento, seja de forma abstrativa ou empírica. Contudo quando pensamos em educação e filosofia, também pensamos no modelo atual de educação e de prática filosófica, que está parcialmente comprometido com a preocupação dos jovens no mercado de trabalho, o que a torna mais um modo de vida mecanicista. A atual sociedade ainda vive momentos de transição por conta do pensamento engessado que perdura de outrora, sendo assim, sabemos o quanto a filosofia é importante para melhor entender esse segmento do atual cenário educacional.

Sabemos que a filosofia traz em sua história, a superação de grandes pensamentos, e de brilhantes ideais, e que sempre buscou os problemas bem como as contradições e questionamentos de todos os tempos, tudo isso ao longo da sua trajetória. Também compreendemos que muitas foram às contribuições dos renomados filósofos, em relação às suas valiosas obras, que ainda hoje perpassam a cadeia do pensamento humano, além de seus tratados e suas ideias que sempre irão refletir sobre o seu tempo e espaço, agindo sempre de forma crítica, transformando e modificando a realidade na qual foram inseridas.

Assim, podemos inferir que a filosofia não apresenta uma finalidade definitiva, nem mesmo uma resposta pronta, ela é, pois, o caminho, seu objeto é seu próprio pensamento e está sendo problematizado a todo o momento. Dessa forma entendemos que através da investigação da racionalidade e dos argumentos lógicos, conseguimos extrair informações, verdades e conhecimentos o que representa a finalidade da filosofia, e dessa forma ser considerada como algo de grande relevância para os estudiosos.

A educação, entretanto, possui seus pressupostos concluídos em seu próprio sistema e tem sua atuação de acordo com determinadas metodologias que a tornam significativamente objetiva e podendo ser considerada como uma atividade pragmática. Apesar disso, é neste contexto pragmático que a filosofia tende a ser apagada, por ser considerada como outra disciplina que não poderá contribuir significativamente em nada para a formação dos educandos, e que por muitas vezes despreparado para tal atividade, e assim não podendo identificar resultados fechados e prontos para serem utilizado imediatamente.

Entretanto, a filosofia, poderá sim vir contribuir para um riquíssimo ensino, atuando de forma atrelada com outras áreas, planejando e intercedendo com sua atividade reflexiva. Assim 
como afirma Saviani:

Eis por que se pode considerar como uma das funções precípuas da filosofia no ensino superior acompanhar reflexiva e criticamente a atividade educacional de modo a explicitar os seus fundamentos, esclarecer a tarefa e a contribuição das diversas disciplinas pedagógicas e avaliar o significado das soluções escolhidas. (SAVIANI,1980, p.30)

É, pois essa uma das grandes razões pelas quais a filosofia não será esquecida, pois é de suma importância para a reflexão no sistema educacional. Assim a filosofia propicia um rico conteúdo reflexivo e crítico que o ambiente educacional precisaria para seu melhor desempenho. Contudo sabemos que recentemente quiseram retirar a "Filosofia e Sociologia" dos currículos escolares, apresentando assim um retrocesso em relação ao desenvolvimento da consciência e reflexão crítica filosófica, questionando assim todas as formas de metodologias, de análise, e de poder, e que se manifestava quando necessário, e que tornava o indivíduo cada vez mais consciente de si mesmo e de seus direitos como homem.

A filosofia permite que o indivíduo possa compreender sua realidade, seus relacionamentos com os demais, de forma aprofundada e sistemática, aplicando métodos e analisando logicamente essas ações. Uma vez que quando o homem não sabe refletir sobre si mesmo, sobre o que o cerca, sobre suas intrínsecas relações, está correndo o risco de perder a sua própria consciência da vida e, por conseguinte tornar-se um subordinado a quem está a exercer o poder. É a partir dessa visão que a filosofia é de posse fundamental nos tempos modernos, de forma que os indivíduos parecem ter os olhos tapados sobre o iminente impacto do tecnicismo, a automatização da vida e de se perturbar, afogando assim as possibilidades de independência e outros.

É necessária uma consciência reflexiva, um olhar mais crítico, um ensino emancipatório, esclarecimento e tantas outras características essenciais que o homem necessita para uma vida livre do sistema que o reprime. Assim a filosofia não poderá ser reservada ao domínio do aluno, é preciso que essa atividade de reflexão também se estenda aos educadores, para que eles também melhorem sua relação com o ensino, refletindo melhor sobre suas práticas e, por consequência, preparar seus alunos para as atividades indispensáveis do pensamento. Como se apresenta na citação a seguir,

Enquanto a educação trabalha com o desenvolvimento dos jovens e das novas gerações de uma sociedade, a filosofia é a reflexão sobre o que e como devem ser ou desenvolver estes jovens e está sociedade. (...) O educando, que é, o que deve ser, qual o seu papel no mundo; o educador, quem é, qual o seu papel no mundo; a sociedade, o que é, o que pretende; qual deve ser a finalidade da ação pedagógica. Estes são alguns problemas que emergem da ação pedagógica dos povos para a reflexão filosófica, no sentido de que esta estabeleça pressupostos para aquela. (LUCKESI,1994, p. 32)

Em conformidade com a afirmação acima, uma filosofia que atua diretamente sobre as 
práticas pedagógicas, se alimentam como pessoas que cercam os jovens, a sociedade e os estudantes. Sendo necessária assim uma ação reflexiva por parte da filosofia com uma ação pedagógica para que se esforce com os problemas que eles exercem na rotina escolar dos alunos. Assim no aspecto pedagógico, a reflexão filosófica tende a desempenhar um papel fundamental na interpretação de temas essenciais para o progresso intelectual do aluno, fomentado assim suas capacidades de reflexão e de criticidade, permitindo se descobrir e descobrir seu papel na sociedade.

É, pois na educação, que recebemos os maiores desafios e mudanças, já que às vezes é uma submissão ao mundo mecânico e que está aliado ao mercado de trabalho é, pois neste ambiente de grandes problemas e de perturbação, uma vez que a conquista de trabalho e de capital, faz com o que os sujeitos se obriguem a disputar por uma vaga, não considerando assim os aspectos da razão e atuando como meros reprodutores do sistema. Dessa forma, devemos realizar e reafirmar um elemento da filosofia no ambiente educacional seja através de suas características e especificidades, a filosofia traz muitas contribuições para o ensino uma vez que uso das possibilidades da reflexão da crítica da emancipação e do diálogo, e que a educação possa ser considerada necessária para melhorar assim a gestão e o poder de transformação, da realidade dos que convivem com ela.

É preciso falar de filosofia e de sua grande importância para a educação, uma vez que o ambiente educacional precisa de uma educação que seja iluminadora, autônoma e que esta não seja aprisionada pelas formas tradicionais da educação.

Dessa maneira, presume-se que a filosofia deva ser inserida na escola dia a dia, representado com ela e refletindo sobre as melhores práticas e modos de produção. É preciso filosofar na escola fortalecendo os alunos para o debate, o diálogo, e o questionamento, retirando-os do senso comum e dessa maneira colocando-os em contato direto com uma crítica da consciência, de maneira que eles não sejam meros reprodutores, mas sim, que se estruturem e se compreendam mesmo sendo criadores de seus próprios raciocínios.

Enfim, o conhecimento filosófico tem por finalidade a compreensão do processo educativo na teoria e na prática, para que o educador tenha capacidade de enfrentar as questões que surgirem ao decorrer do processo educativo, relacionando-se criticamente e reflexivamente com a prática educativa na busca de mudanças. (FREIRE, 2004)

\section{CONCEITUANDO EDUCAÇÃO NA PERSPECTIVA FILOSÓFICA}

Segundo Cortella (1994) Educação (do latim educare) no sentido formal é todo o processo contínuo de formação e ensino aprendizagem que faz parte do currículo dos estabelecimentos oficializados de ensino, sejam eles públicos ou privados. Já no sentido técnico, a educação é o processo 
contínuo de desenvolvimento das faculdades físicas, intelectuais e morais do ser humano, a fim de melhor se integrar na sociedade ou no seu próprio grupo.

Todavia a educação é uma arte, cuja prática demanda ser aperfeiçoada por muitas gerações. E cada geração, de posse dos conhecimentos das gerações anteriores, está sempre mais bem aparelhada para exercer uma educação que desenvolva todas as disposições naturais na justa proporção e de conformidade com a finalidade daquelas, e, dessa forma, guie toda a humana espécie a seu destino. A Providência quis que o homem extraísse de si mesmo o bem e, por assim dizer, desse modo lhe fala: "Entra no mundo. Coloquei em ti toda espécie de disposições para o bem. Agora compete somente a ti desenvolvê-las e a tua felicidade ou a tua infelicidade depende de ti”. (KANT, 2002)

Numa ótica maior, educação significa o meio em que os hábitos, costumes e valores de uma determinada comunidade são transpassados ou transferidos de uma geração para outra. Diante disso, a educação vai se configurando através de experiências vividas e situações presenciadas e ainda por cada indivíduo ao longo da sua história. Assim o conceito de educação permeia o nível de cortesia, delicadeza e de civilidade demonstrada por um indivíduo e a sua capacidade e necessidade de socialização.

Segundo Freire (1980), a educação se apresenta como um processo dialógico e comunicativo e que passa pela ideia de uma união entre interlocutores que constroem múltiplos conhecimentos, ensinam e aprendem de modo simultâneo. Para Freire, o homem é tido como um ser consciente e intencional que, num processo educativo, procura construir uma relação dialética com seus interlocutores, relação na qual todos ganham, uma vez que todos buscam suas libertações. São conexões, enfim, que partem do subjetivo para tomarem corpo na objetividade, e porque são dialéticas, tornam-se solidárias.

Ainda em consonância com o filósofo pedagogo René Hubert, a educação é um conjunto de ações e influências que são exercidas voluntariamente por um ser humano em outro, normalmente de um ser adulto em um jovem. Contudo essas ações têm a pretensão de alcançar um determinado propósito no indivíduo para que ele possa desempenhar alguma função nos contextos culturais, políticos, sociais e econômicos, de uma sociedade. No sentido tecnicista, a educação é o método contínuo de evolução das faculdades intelectuais, físicas, e morais do ser humano, com o intuito de melhor se inserir na sociedade ou no seu próprio grupo. (TOMAZONI, 2014)

No Brasil, de acordo com a Lei de Diretrizes e Bases, a Educação está dividida em dois níveis, que são: à educação básica e o ensino superior. De maneira que a educação básica compreende a Educação Infantil, o Ensino Fundamental e o Ensino Médio, já o ensino superior consiste no efetivo 
meio de formação e aperfeiçoamento do indivíduo em uma determinada área. Na metodologia do processo educativo em estabelecimentos de ensino, os conhecimentos e habilidades são repassados para as crianças, jovens e adultos sempre com o objetivo de desenvolver o raciocínio dos alunos, ensinando a pensar sobre diferentes problemas, ajudando assim no crescimento intelectual e na formação de cidadãos que sejam capazes de gerar transformações positivas na sociedade. Contudo a educação não se restringe apenas as normas morais e intelectuais, mas também poderá estar atrelada com o aspecto físico, como se apresenta no caso da educação física.

É sabido que a educação vem rodeando o homem durante toda a sua história de vida, ou seja, desde seu surgimento, e está presente ao seu lado a todo o momento. É, pois na educação e através dela que o homem não somente se encontra com seus conhecimentos adquiridos ao longo da história, e com o mundo, mas também como poderá transformar os aspectos de sua existência por meio dela. Assim a educação é o meio pelo qual os homens se adaptam para assim conhecer e poder alterar o seu meio, ela é imprescindível ao desenvolvimento cultural do homem, pois está o rodeando em seu modo de vida e sua relação com os outros homens. Uma vez que a educação é assim indispensável ao homem. Mas, há outro âmbito que é tido também como essencial: o filosófico.

A educação é um tipo "que-fazer" humano, ou seja, um tipo de atividade que se caracteriza fundamentalmente por uma preocupação, por uma finalidade a ser atingida. A educação dentro de uma sociedade não se manifesta como um fim em si mesma, mas sim como um instrumento de manutenção ou transformação social. Assim sendo, ela necessita de pressupostos, de conceitos que fundamentem e orientem os seus caminhos. A sociedade dentro da qual ela está deve possuir alguns valores norteadores, que também se amparam da filosofia. (LUCKESI, r990, p. 3I)

Ponderando que a educação é conduzida por conceitos, valores e finalidades, cabe então a nós refletir sobre o verdadeiro sentido e valor que a educação tem para a sociedade. Para que assim possamos entender como a educação e seu direcionamento filosófico é muito importante, para assim melhor entendermos as três tendências filosóficas e políticas que se constituíram ao longo da prática educacional, na visão de Luckesi (1994). Segundo o autor: "esses três grupos de compreensão no sentido da educação na sociedade podem ser apresentados respectivamente, pelos seguintes conceitos: educação como redenção; educação como reprodução; e educação como meio de transformação da sociedade" . O entendimento dessas perspectivas da educação pode propiciar uma prática pedagógica com valor significativo de consciência, permitindo ao educador atuar tendo em vista uma construção mais política e filosófica do seu papel social. Tais habilidades filosóficas se configuram pelo

${ }^{2}$ LUCKESI, Cipriano Carlos. Filosofia da educação. 24 ed. São Paulo: Cortez, 1994. Pg.37 
esclarecimento do sentido da educação na e para a sociedade.

Como se apresenta;

Nesse contexto, a educação assume uma significativa margem de autonomia, na medida em que deve configurar e manter a conformação do corpo social. Em vez de receber as interferências da sociedade, é ela que interfere, quase que de forma absoluta, nos destinos do todo social, curando-o de suas mazelas. Este é um modo ingênuo de compreender a relação entre educação e sociedade. (LUCKESI, 1994, p. 38)

Educação e filosofia nunca foram, nem são caminhos que andam em direções contrarias, pois sempre estiveram olhando o homem em sua existência como tal. Todavia a filosofia, desde seu surgimento não se preocupou apenas em observar o homem, mas trouxe ricas contribuições de filósofos que pensaram a forma de educar por excelência. Temo como exemplo disso: a Maiêutica de Sócrates, os Diálogos de Platão, a Metafisica de Aristóteles e tantas outras obras que se seguem, posterior aos clássicos, do pensamento filosófico. Sendo assim, os filósofos não tinham apenas a pretensão de informar, mas buscavam também educar. A retomada a essas obras e a autores de épocas passadas tendem a contribuir em grande escala para o maior entendimento da problemática humana de cada tempo e são de grande valor educacional. Dessa maneira é fundamental que à filosofia esteja contida no meio metodológico da educação como forma de ampliar e fortalecer os vínculos educacionais.

De acordo com Aranha (1996), são no âmbito educacional, que a filosofia expõe para o educador as questões de ordem antropológicas, axiológicas, epistemológicas e políticas. Assim, esse questionamento brusco torna a atividade educacional mais esclarecida. Entretanto ao observar todos os questionamentos sobre o que é educação, a autora pontua que, "a filosofia contribui para que ela não resulte em adestramento ou qualquer tipo de falsa educação, nem que a pedagogia se torne dogmática”. Pondera-se que, a Filosofia contribui com a educação para que a mesma não se torne uma simples forma de treinamento.

Para Freire (1979), a prática do educar implica uma busca contínua do homem em ser mais, o que, por sua vez, implica que seja ativo na construção do saber, ou seja: sujeito da própria educação, e não objeto dela. Dessa maneira a educação pode ser entendida como sendo um método de socialização dos indivíduos. Ao adquirir educação, a pessoa assimila e recebe conhecimentos. Uma vez que a educação também envolve uma sensibilização 
cultural e de comportamento, onde as novas gerações adquirem as formas de se estar na vida das gerações anteriores.

Assim a educação é concebida como produção do saber, ou seja, a aquisição do conjunto de conhecimentos que se possui, sendo o homem, capaz de elaborar ideias, e ainda uma diversidade de conceitos. (SAVIANNI, I990)

\section{COMO O FILOSOFAR CONTRIBUI PARA A PRÁTICA DOCENTE NO ENSINO SUPERIOR NOS CURSOS DE LICENCIATURA ${ }^{3}$ ?}

A educação ao cumprir o papel na formação do sujeito está amparada pela reflexão filosófica que pode levar os indivíduos a pensarem sobre uma maneira diferente as suas vidas, e suas formas de resistência, reconhecendo assim, que são manipulados e abusados pelos portadores do poder. Entretanto, o mais importante nisso tudo é que ela os faz ver como são capazes de alterar suas relações no meio social, fazendo assim com que lutem de forma organizada e mobilizada pelo seu processo de libertação e de emancipação. Contudo a atitude filosófica vem a surgir quando o educador incita a reflexão crítica sobre as adversidades existentes entre entender e analisar cada um dos problemas que encontram, seja de ordem social, política, ou ainda relacionada à família, entre outros que permeiam no contexto da sala de aula.

Para Freire (2006) as incumbências da filosofia são provocar, instigar, analisar, bem como incitar os indivíduos para um melhor entendimento do mundo, ressaltando a importância de se nortear como sujeito construtor da sua própria realidade. A filosofia sugere uma contemplação profunda da realidade para que se possa entender que a história se constitui de possibilidades e não de determinações, atribuindo aos indivíduos, uma chance de construir a sua realidade, de se envolver, de ter curiosidade, de questionar algo que acontece de uma forma e não de outra. Assim o ser humano, como indivíduo dotado de razão, é capaz de conquistar o conhecimento através da experiência de vivência no mundo e sendo também capaz de se adaptar, mas, não uma adaptação ordenada e sim, uma que se propõe à mudança. É importante esclarecer, que o indivíduo que tende à mudança, se caracteriza como um ente capaz de interferir nos rumos de que se toma a sociedade e é por esse motivo e tantos outros que não se pode aceitar a neutralidade de um ser e nem do saber.

De modo efetivo, se a filosofia é realmente um pensamento sobre os obstáculos que a

\footnotetext{
3 O vocábulo docente veio do latim docens, docentis que era o particípio presente do verbo latino docere que significa "ensinar". Docente seria aquele que ensina, instrui e informa. CUNHA, Antônio G. da. [1982] Dicionário etimológico Nova Fronteira da língua portuguesa. Rio de Janeiro: Nova Fronteira, 1997.
} 
realidade apresenta, todavia ela não é qualquer tipo de reflexão. Para que uma reflexão possa ser adjetivada de filosófica, é preciso que se satisfaça uma série de exigências que se apresentam em apenas três requisitos: a radicalidade, o rigor e a globalidade. Dessa forma a reflexão de ordem filosófica, para ser tal, deve ser radical, rigorosa e de conjunto. Assim a reflexão filosófica é tida como radical porque se preocupa com as raízes dos problemas, investigando-os diretamente na sua essência, nos seus fundamentos e na sua origem. É rigorosa, pois ela possui uma sistematização própria, aplica métodos específicos para atingir determinada finalidade, uma vez que é através desse mecanismo que ela irá favorecer uma compreensão filosófica mais eficaz. E por fim ela se apresenta em conjunto, pois ela não se limita a pequenas questões, mas se aplica a totalidade e dessa maneira tenta construir o raciocínio a partir da conjectura total do problema. (SAVIANNI, 1996 p.16)

Contudo, toda essa sistemática se correlaciona com a prática educativa porque o professor precisa dentro da sala de aula junto com os alunos encarar os problemas e refleti-los de maneira filosófica, tentando assim encontrar a raiz desses problemas, suas causas e fundamentos, de maneira que deva pensar que está lidando com o ser humano que é cheio de subjetividade de modo a fazê-lo encontrar-se, no seu próprio meio, uma vez que tudo isso está muito além do que as pequenas coisas que são postas pelo próprio sistema educacional.

A reflexão filosófica tem por finalidade o entendimento da ação educativa na teoria e na prática, de maneira que o educador desenvolva a capacidade de enfrentar as questões que se apresentarem ao longo do processo, acompanhando de forma sistemática e reflexiva, estimulado assim a criticidade na prática educativa na busca de mudanças. Desta forma, Freire ( $\left.{ }^{2} 004\right)$ considera que:

\footnotetext{
O que importa, na formação docente, não é a repetição mecânica do gesto, este ou aquele, mas a compreensão do valor dos sentimentos, das emoções, do desejo, da insegurança a ser superada pela segurança, do medo que, ao ser "educado", vai gerando a coragem. (FREIRE 2004, p. 45 apud SIQUEIRA; PRATES; PORTO, 2015 p. 18)
}

Para Freire, o que deve realmente ser importante para a formação docente é o entendimento dos valores emotivos, e a superação dos medos do ensino-aprendizagem que vai instituindo assim a determinação para ensinar. Para o autor é, pois na formação permanente dos professores, onde ocorre o momento fundamental, ou seja, o momento da reflexão crítica sobre a prática. Onde se pensa criticamente a atual prática pedagógica, e também a de outrora, e dessa maneira repensar o que poderá melhorar na próxima prática. Destarte, a filosofia aliada com a educação desenvolve uma das ações mais importantes da prática educativa-critica, onde o ensinar requer uma reflexão crítica sobre a própria prática. (FREIRE, 2004. p39)

Todavia, a filosofia na formação docente deverá representar uma das disciplinas 
indispensáveis na formação de todo educador, fundamentando assim a sua ação de modo a subsidiálo para a construção da reflexão crítica e esclarecedora. A atitude filosófica de modo dirigida é um dos meios que permite atingir os propósitos e objetivos sociopolíticos da educação, como fator que indica a construção do conhecimento que não seja tido como senso comum, mas sim filosófico.

Savianni (1990) afirma que muitas vezes ocorre de a filosofia estar em um ambiente inalcançável a alguns educandos, pelo simples fato de que os educadores os afastam desse ambiente, reduzindo assim, a meros conceitos, pré-formulados em que o aluno se agarra, uma vez que eles consideram à prática do filosofar impossível para sua capacidade de interpretação. Isso é o fim para esta disciplina, dessa maneira faz-se necessário que esta seja tão valorizada que não seja uma simples experiência cotidiana, na vida dos estudantes. Entretanto a filosofia deve ser transpassada na sua ligação com a vida cotidiana, de modo que seja o melhor possível para a percepção de bem-estar e segurança. Sendo assim, quando a Filosofia atua de várias maneiras, os pressupostos teóricos da educação e da prática pedagógica, resultam no estudo crítico, que constituem um componente essencial e fundamental na capacitação dos educadores.

Segundo Freire (2006), o saber é tido como imprescindível na prática educativa assim como a análise da ação pedagógica que também é necessária ao educador, fazendo assim a mobilização do educando como sujeito da ação, conhecendo dessa forma as diferentes problemáticas que caracterizam a sua própria realidade e a de seus educandos, devendo o mesmo interagir no mundo com ele. Uma vez que ensinar exige que o educador acredite na mudança, devendo ele escolher metodologias que proporcionem ao educando o interesse e a curiosidade pelo conhecimento, formando os educandos para atuar e intervir ativamente na realidade. Portanto para refletir sobre o processo de ensino-aprendizagem no contexto educacional é necessário incluir a ideia de inacabamento, uma vez que o ser que toma consciência dos seus atos e assimila a capacidade de aprender, não apenas para se adaptar á realidade, mas com o anseio de reconstruí-la.

Depreende-se, que a filosofia impede a autoimposição de regras e valores na prática pedagógica, devendo-se propor um modelo de educação que vise à ordenação política do educador, a assimilação da existência do homem como um ser capaz de pensar e de agir para melhorar sua própria realidade, e seus meios materiais de existência. Dessa maneira a atividade filosófica surge no momento que o educador provoca a reflexão crítica sobre os problemas existentes. Sendo assim, cabe ao educador compreender e analisar os problemas do contexto de sua sala de aula.

Com efeito, a filosofia está sendo considerada fundamental na atualidade uma vez que os indivíduos parecem está de olhos fechados sobre o impacto do tecnicismo e da mecanização da vida. Tornando a si e aos outros seres alienados afogando assim as possibilidades de emancipação de si e 
dos outros. Entretanto é necessária uma consciência mais reflexiva um olhar crítico e um ensino que seja emancipador, é necessário esclarecimento e tantas outras coisas que são fundamentais para que o sujeito possa assim viver uma vida livre. (BEZERRA, 2015, p. 7)

É nesse cenário que a filosofia vem colaborar no meio educacional, isso através de suas particularidades, saindo do senso comum e ampliando a prática filosófica, contribuindo assim com um melhor desenvolvimento e riqueza no que concerne às ações educacionais, em conjunto com outras áreas que não são menos importantes que a filosofia, mas que podem amparar uns a outras para um melhor aperfeiçoamento das metodologias, diálogos e práticas que necessitam de reflexão. Destarte, Savianni (1980) pondera que:

Para imprimir maior coerência e consistência à sua ação. É mister que o educador se eleve do senso comum ao nível da consciência filosófica de sua própria prática, o que implica detectar e elaborar o bom senso que é o núcleo válido de sua atividade. E tal elaboração passa pelo confronto entre as experiências pedagógicas significativas vividas pelo educador e as concepções sistematizadas da filosofia no ensino superior com outras áreas. Com isso será possível explicitar os fundamentos de sua prática e superar suas inconsistências, de modo a torná-la coerente e eficaz. (SAVIANNI, I98o, p. 8)

Logo, para atingir tais fins é imprescindível a formação de educadores para que a prática reflexiva aqui defendida seja realmente efetivada e que os educandos tenham o anseio merecido para com ela, ajudando-os a captarem, apontando, e afirmando a valor da filosofia para suas vidas dentro e fora da instituição escolar.

Portanto o papel da filosofia na formação do docente no ensino superior envolve o questionamento, a denúncia, a reflexão a crítica profunda, entre outros fundamentos, que são indispensáveis, tudo isso tendo como base a análise do contexto histórico, político e social vigente. Desta forma, o caminho da transformação passa pela educação e pela filosofia uma vez que são estas que ajeitam o território em que o educando deve seguir seu percurso na perspectiva de um modo de vida onde ele seja o construtor, ao passo de que elas executam um papel crucial na vida e na metodologia de ensino e de instrução do educador, que se empenha fervorosamente para efetivar o saber e a consciência filosófica do educando. (NUNES. 2012, p. 15)

Em síntese a filosofia é intrinsecamente indispensável na formação do docente no ensino superior, isso quando ela é encarada como uma reflexão radical, rigorosa e de conjunto sobre os problemas que a realidade educacional apresenta. Ao passo de que no âmbito educacional, a Filosofia possibilita refletir criticamente, questionar a realidade natural e humana em sua dimensão existencial, política, social, e no campo educativo busca fazer uma reflexão crítica acerca das práticas educativas fomentando assim o senso crítico e filosófico do educador. (SAVIANNI, 1996 p.16) 


\section{CONSIDERAÇÕES FINAIS}

Este estudo ponderou que a filosofia permeia o homem a todo o momento, em sua vivência cotidiana, quando ele se questiona sobre algo, quando se sente incomodado com certos valores, quando ele questiona as leis e as ordenações políticas, fazendo assim o uso preciso de sua consciência crítica. E é a partir desse contexto, que a filosofia, bem como a reflexão filosófica, deve ser transpassada em sua conexão com o cotidiano, para que o educando a perceba como influência para ele, e que ela está acompanhando-o, e que é indispensável no seu dia a dia, por estar contida nele.

Após a leitura e reflexão acerca da pesquisa bibliográfica desse estudo, pode-se considerar o real valor e a importância da Filosofia na formação do docente no ensino superior, assimilando que a reflexão filosófica é muito necessária, mas que não tem o intuito de definir elementos de objetivo direto da educação, assim como afirma Saviani (2009), a filosofia no ensino superior não tem como função definir a priori princípios e objetivos para a educação; também não se reduz a uma teoria geral da educação enquanto sistematização dos seus resultados. Portanto sua função é direcionar reflexivamente e criticamente a atividade educacional, de maneira a esclarecer os seus fundamentos, determinando a tarefa e a contribuição das várias disciplinas pedagógicas e assim avaliando o significado das soluções adotadas.

Com efeito, entendemos que na formação de educadores é indispensável uma base curricular bem alicerçada e que possa englobar múltiplas disciplinas pedagógicas, propiciando o desenvolvimento dessa formação. Contudo a Filosofia no ensino superior caracteriza-se como uma das disciplinas indispensáveis na formação de todo educador, pois ela tem o papel de fundamentar a sua prática de maneira a fornecer subsídios para a construção do conhecimento crítico e esclarecedor dos educandos.

Tendo em vista que a educação visa o homem, é adequado iniciar por uma reflexão sobre a realidade humana. Assim, a tarefa da Filosofia no ensino superior será permitir aos educadores um método de reflexão que venha lhes permitir encarar os problemas educacionais, adentrando na sua complexidade e posicionando a solução de questão. Sendo assim, a questão problemática do exercício da atividade educacional, é o que explicita a relevância e a carência da reflexão filosófica para o educador. Destarte, é de grande valor que o educador possa ter desenvolvido uma habilidade de refletir complexamente, rigorosamente, senão suas possibilidades de sucesso estarão reduzidas.

Realizado, pois este estudo cabe aos educadores à tarefa pedagógica de assumirem com mais determinação a formação humana, favorecendo e evidenciando uma reflexão 
crítica a nível filosófico, onde possa propiciar inúmeras possibilidades e oportunidades de atuar na educação, com o anseio de melhorá-la em favor do crescimento e desenvoltura dos educandos. Portanto essa tarefa se caracteriza no cenário atual como indispensável e inadiável.

\section{REFERÊNCIAS}

ARANHA, Maria L. de Arruda. Filosofia da educação. São Paulo: Moderna, I989. . História da Educação. 2 ed. São Paulo: Moderna, 1996.

BRASIL, Lei de Diretrizes e Bases. Lei no 9.394/96, de 20 de dezembro de 1996.

BEZERRA, M. A. S., Neto, J. C. R., Claudia, M., Henrique, C., \& Pereira, V. FILOSOFIA E EDUCAÇÃO: UMA RELAÇÃO NECESSÁRIA. I ed. Paraíba, 2015.

CHAUÍ, Marilena. Convite à filosofia. São Paulo: Ática, 2010.

CORTELLA, Mario Sérgio. A escola e o conhecimento: fundamentos epistemológicos e políticos. Ed. 3ª . São Paulo: Cortez, 1994.

CUNHA, Antônio G. da. [1982] Dicionário etimológico Nova Fronteira da língua portuguesa. Rio de Janeiro: Nova Fronteira, 1997.

FERNANDES, Vladimir. Filosofia, ética e educação na perspectiva de Ernst Cassirer. FEUSP: Tese de doutorado, 2006, cap. 4)

FREIRE, Paulo. Pedagogia da autonomia: saberes necessários à prática educativa. 33 ed. São Paulo: Paz e Terra, 2006.

. Pedagogia da autonomia: Saberes necessários a prática educativa. 30 ed. São Paulo: Paz e Terra, 2004.

. Conscientização - teoria e prática da libertação. São Paulo: Cortez \& Moraes, 198o.

Educação e mudança. Tradução de Moacir Gadotti. Rio de Janeiro: Paz e Terra, 1979.

KANT, Immanuel. Sobre a pedagogia. Tradução de Francisco Cock Fontanella. 3.a Ed. Piracicaba: Editora UNIMEP, 2002.

LUCKESI, Cipriano Carlos. Filosofia da educação. 24 ed. São Paulo: Cortez, 1994.

NUNES, Maria do Carmo Portela. A importância da filosofia na formação do docente no ensino superior: uma reflexão a partir de substratos teóricos e pesquisa de campo em uma 
universidade em Paranaíba-PI. IV Fórum internacional de pedagogia - FIPED. Paranaíba PI / Brasil. 2012.

SAVIANI, Dermeval. Educação: do senso comum à consciência filosófica. I8 ed. Campinas, SP: Autores Associados, 2009.

Contribuições da Filosofia para a Educação. EM ABERTO, v. 9, n.45, p. 3-9, 1990. Capítulo 2 do livro - Educação: do senso comum à consciência filosófica.

Educação: do senso comum à consciência filosófica. São Paulo, Autores Associados/Cortez, 1980

Educação brasileira: estrutura e sistema. São Paulo, Saraiva, 1973, p.68.

SIQUEIRA, Eliette Cardoso; PRATES, Isabella Tolentino; PORTO, Késia Rodrigues Silveira. A IMPORTÂNCIA DA FILOSOFIA E DA EDUCAÇÃO NA FORMAÇÃO DOCENTE Disponivel:http://www.copednm.com.br/quarto/images/anais_4/formacao_ professores/A_IMPORTANCIA_DA_FILOSOFI_NA_FORMACAO_DOCENTE. pdf: Acesso em or. Out. 2017.

TOMAZONI, Ana Maria Ruiz. Práticas e reflexões sobre educação: uma narrativa interdisciplinar. Tese de doutorado. Programa de Educação/Currículo. São Paulo: PUC/SP, 2014 . 